\title{
Article
}

\section{The Structure and Mechanical Properties of Hemp Fibers-Reinforced Poly( $\varepsilon$-Caprolactone) Composites Modified by Electron Beam Irradiation}

\author{
Rafał Malinowski ${ }^{1, *(1)}$, Aneta Raszkowska-Kaczor ${ }^{1}$, Krzysztof Moraczewski ${ }^{2}{ }^{(D}$, Wojciech Głuszewski ${ }^{3}{ }^{(0)}$, \\ Volodymyr Krasinskyi ${ }^{4}$ (D) and Lauren Wedderburn ${ }^{1}$
}

1 Łukasiewicz Research Network-Institute for Engineering of Polymer Materials and Dyes, $55 \mathrm{M}$. Skłodowska-Curie Street, 87-100 Torun, Poland; aneta.kaczor@impib.lukasiewicz.gov.pl (A.R.-K.); lauren.wedderburn@impib.lukasiewicz.gov.pl (L.W.)

2 Institute of Materials Engineering, Kazimierz Wielki University, 30 Chodkiewicza Street, 85-064 Bydgoszcz, Poland; kmm@ukw.edu.pl

3 Institute of Nuclear Chemistry and Technology, 16 Dorodna Street, 03-195 Warsaw, Poland; w.gluszewski@ichtj.waw.pl

4 Department of Chemical Technology of Plastics Processing, Lviv Polytechnic National University, 12 Stepan Bandera Street, 79-013 Lviv, Ukraine; vkrasinsky82@gmail.com

* Correspondence: malinowskirafal@gmail.com; Tel.: +48-53-060-0220

Citation: Malinowski, R.; Raszkowska-Kaczor, A.; Moraczewski, K.; Głuszewski, W.; Krasinskyi, V.; Wedderburn, L. The Structure and Mechanical Properties of Hemp Fibers-Reinforced Poly ( $\varepsilon$-Caprolactone) Composites Modified by Electron Beam Irradiation. Appl. Sci. 2021, 11, 5317 https://doi.org/10.3390/app11125317

Academic Editor:

Alessandro Pegoretti

Received: 30 April 2021

Accepted: 4 June 2021

Published: 8 June 2021

Publisher's Note: MDPI stays neutral with regard to jurisdictional claims in published maps and institutional affiliations.

Copyright: (c) 2021 by the authors. Licensee MDPI, Basel, Switzerland. This article is an open access article distributed under the terms and conditions of the Creative Commons Attribution (CC BY) license (https:// creativecommons.org/licenses/by/ $4.0 /)$

\begin{abstract}
The need for the development of new biodegradable materials and modification of the properties the current ones possess has essentially increased in recent years. The aim of this study was the comparison of changes occurring in poly( $\varepsilon$-caprolactone) (PCL) due to its modification by high-energy electron beam derived from a linear electron accelerator, as well as the addition of natural fibers in the form of cut hemp fibers. Changes to the fibers structure in the obtained composites and the geometrical surface structure of sample fractures with the use of scanning electron microscopy were investigated. Moreover, the mechanical properties were examined, including tensile strength, elongation at break, flexural modulus and impact strength of the modified PCL. It was found that PCL, modified with hemp fibers and/or electron radiation, exhibited enhanced flexural modulus but the elongation at break and impact strength decreased. Depending on the electron radiation dose and the hemp fibers content, tensile strength decreased or increased. It was also found that hemp fibers caused greater changes to the mechanical properties of PCL than electron radiation. The prepared composites exhibited uniform distribution of the dispersed phase in the polymer matrix and adequate adhesion at the interface between the two components.
\end{abstract}

Keywords: poly(E-caprolactone); hemp fibers; composites; irradiation; mechanical properties; biodegradable polymers

\section{Introduction}

One of the most important biodegradable polymers, produced from petroleum resources, is poly( $\varepsilon$-caprolactone) (PCL) [1-5]. Its physico-chemical properties are generally beneficial and the material may play a key role in many branches of the economy (both in specialised and mass applications). However, the PCL properties need to be modified for some applications. It concerns, for example, properties such as its thermal resistance due to low melt temperatures $\left(58-60^{\circ} \mathrm{C}\right)$ or its barrier properties for some gases [6-8]. PCL mechanical properties can also be modified with the use of mineral or vegetable fillers that simultaneously lower the price of the polymer. It is important because PCL in its pristine form is generally more expensive than conventional polymers and even some biodegradable ones such as PLA [9-13] or TPS [14-17].

PCL properties can be modified by different methods. Various types of PCL polymer blends as well as composites and nanocomposites are most often obtained. The most well- 
known PCL blends are: (i) PCL/TPS [18-20], (ii) PLA/PCL [21-24] or (iii) PCL/PBAT [25]. PCL blends containing non-biodegradable polymers also exist, e.g., PCL/PVC [26] or PCL/PBT [27]. Another significant group is PCL composites with natural fillers, including plant fibers [28-35]. Other known methods of PCL property modification refers to processes such as copolymerization, grafting and crosslinking [36-41].

In this study, we proposed a combination of two methods to modify PCL properties. The first method refers to obtaining PCL composites with hemp fibers (HF) and the second method is related to irradiation of such obtained composites with the use of electron radiation. Our literature review revealed only a few studies on PCL/HF composites. For example, the experimental work carried out by Dhakal et al. [42] investigated the reinforcement efficiency of hemp fibers with different fiber aspect ratios on PCL-based biocomposites and compared the influence of these aspect ratios on moisture absorption behavior along with the tensile, flexural and impact properties of hemp fiber/PCL biocomposites. In another study by this author [43], the effects of variable mean hemp fiber content on nano-mechanical (hardness, modulus, elasticity and plasticity), surface and thermal properties of hemp fiber/polycaprolactone biocomposites were studied. Dhakal et al. [44] presented some test results of PCL/HF composites and compared them to the results of similar composites, i.e., those containing date palm fibers. Studies on PCL/HF composites have also been carried out by Beaugrand et al. [45], who examined, among other parameters, the effect of processing conditions on defibration and mechanical properties. Many more studies on PCL composites with other types of natural fibers have been conducted. Examples of such studies are presented in a review publication by Wahit et al. [46]. The authors of this publication concluded that green composites with enhanced mechanical properties can be successfully prepared. They also showed that natural fibers reduce the price of these composites and expand their application areas, which in turn could attract public interest.

Key studies on the modification of PCL properties also concern its radiation modification, especially in cases of modified PCL to be applied in medicine or tissue engineering. Studies in this area were conducted mainly with the use of gamma radiation or electron radiation [47-49]. These studies indicated that PCL, when subjected solely to irradiation, does not form a significant amount of gel fraction and the degradation processes are not dominant at the same periods of time. Good crosslinking of PCL may be successfully carried out by using crosslinking agents such as triallyl isocyanurate (TAIC) [49-51]. Then, with the appropriately selected irradiation conditions, PCL can be completely crosslinked. As a consequence of this, it will not flow and its degree of crosslinking will be more than $90 \%$.

Literature analysis revealed that, there are no known studies on the combined effect of both electron radiation and natural hemp fibers on PCL properties, in particular, mechanical ones. Admittedly, some similar studies can be found in the literature, however, they concern either other types of natural fibers or different polymers. For example, Rytlewski et al. investigated the effect of electron radiation on the properties of PLA [52] or PCL [53] containing $20 \%$ flax fibers with the addition of $1 \%$ to $3 \%$ TAIC. Understanding the combined effect of electron radiation and hemp fibers on the structure and mechanical properties of PCL is interesting from both cognitive and utilisation aspects. From the cognitive aspect it is important to know the relationship between the radiation dose, the amount of fibers in the polymer matrix and the properties of the obtained materials. From the utilisation aspect, modification of PCL with hemp fibers and electron irradiation has been carried out to obtain new materials susceptible to biodegradation. Furthermore, the use of hemp fibers in our study may assist in reducing the adverse effects of PCL's partial crosslinking and on its biodegradability.

This inspired the authors of the present article to undertake investigations aimed at the comparison of the structure and mechanical properties of PCL/HF composites modified by electron radiation with doses in the range of 10-90 kGy. The comparison of changes in (i) the structure of the fibers extracted from obtained composites; (ii) the surface geometrical 
structure of sample fractures; (iii) the tensile strength; (iv) the elongation at break; (v) the flexural modulus; and (vi) the impact strength have been presented in this paper.

\section{Experimental}

2.1. Materials

The following materials were used in this study:

- $\quad$ Poly(E-caprolactone) (PCL), type CAPA6800 with a measured melt flow rate (MFR) of $5.1 \mathrm{~g} / 10 \mathrm{~min}\left(2.16 \mathrm{~kg}, 190^{\circ} \mathrm{C}\right)$, density of $1.15 \mathrm{~g} / \mathrm{cm}^{3}$ and average molecular weight of ca. $82 \mathrm{kDa}$ was supplied by Ingevity UK Ltd. (Warrington, UK);

- Natural hemp fibers (HF), at $6 \mathrm{~mm}$ long, were purchased from the Institute of Natural Fibers and Medicinal Plants in Poznan (Poland). The cut hemp fibers' structure is shown in Figure 1 were applied as the PCL filler.

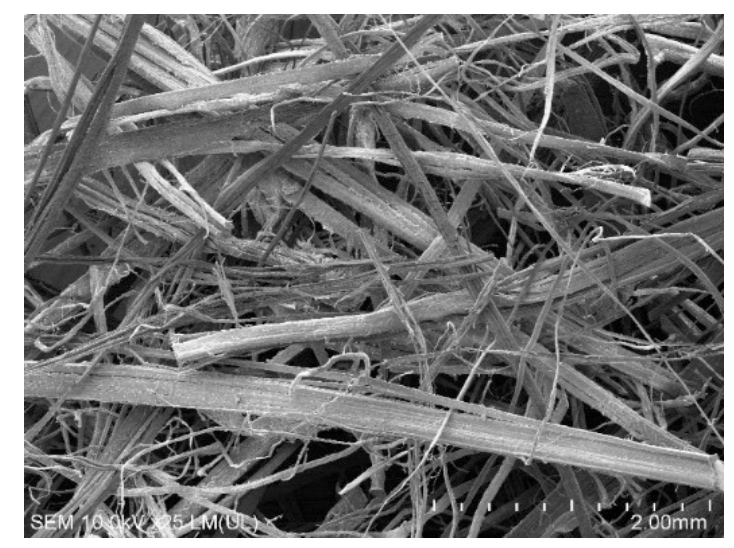

Figure 1. SEM image of hemp fibers (HF) structure.

\subsection{Apparatus}

The following devices were utilised to prepare and investigate the irradiated PCL composites:

- Co-rotating twin screw extruder of type BTSK 20/40D (Bühler, Germany), equipped with 20-mm diameter screws and $\mathrm{L} / \mathrm{D}$ ratio of 40 intended to produce granulated PCL composites;

- Screw injection molding machine of type Battenfeld Plus 35/75 (Battenfeld GmbH, Solingen, Germany), equipped with 22-mm diameter screw and L/D ratio of 17 designed to produce standard dumbbell-shaped and bar-shaped specimens;

- Linear accelerator of type Elektronika 10/10 (Institute of Nuclear Chemistry and Technology in Warsaw, Poland) with energy of electrons $10 \mathrm{MeV}$ and electron beam power $10 \mathrm{~kW}$ for irradiation of PCL composites;

- Shaker of type Unimax 1010 (Heidoplh, Germany) was used to extract fibers from obtained composites;

- $\quad$ Scanning electron microscope (SEM) of type Hitachi SU8010 (Hitachi, Japan) was used to examine the structure of $\mathrm{HF}$ as well as surface geometrical structure of sample fractures;

- Tensile testing machine of type TIRAtest 27025 (TIRA Maschinenbau GmbH, Schalkau, Germany) was used to examine mechanical properties under static tension and static three-point bending;

- Pendulum Impact Tester of type IMPats-15 (ATS FAAR, Novegro-Tregarezzo, Italy) was intended for the determination of Charpy impact strength.

\subsection{Methods}

Extrusion of the pristine PCL and granulated PCL composites was performed at the following temperatures of particular cylinder zones of the co-rotating twin screw extruder: 
$140{ }^{\circ} \mathrm{C}, 150{ }^{\circ} \mathrm{C}, 160^{\circ} \mathrm{C}$ and $165^{\circ} \mathrm{C}$. The temperature of the extrusion die head was $160{ }^{\circ} \mathrm{C}$ and the screw rotational speed was constant at $250 \mathrm{~min}^{-1}$. The screws were in a specific configuration that facilitated adequate dispersion and distribution of HF in the PCL matrix. Moreover, the screws consisted of elements providing intensive HF grinding to obtain fine fractions. Prior to extrusion, HF was dried at $110^{\circ} \mathrm{C}$ for $24 \mathrm{~h}$. PCL was not subjected to drying. Free degassing of any possible released residual moisture was applied at the screws with lengths of $\mathrm{L} / \mathrm{D}=22$ and $\mathrm{L} / \mathrm{D}=32$, respectively. PCL and HF were introduced into the extruder from volume feeders in such proportions that PCL composites with $\mathrm{HF}$ contents equal to 2.5, 5, 10 and $20 \mathrm{wt} \%$ were obtained. The percentages of fibers added were chosen based on our previous studies [52,53]. The extrudate was cooled in a water bath at $15^{\circ} \mathrm{C}$ and then dried on a conveyor belt in a stream of dry air and finally granulated. The obtained composites in the form of cylindrical granules (height $5 \mathrm{~mm}$ and base diameter $3 \mathrm{~mm}$ ) were dried at $50{ }^{\circ} \mathrm{C}$ for $24 \mathrm{~h}$ to eliminate residual moisture. The prepared samples of the granulated composites were denoted as CF2.5, CF5, CF10 and CF20, where $C$ denotes poly( $\varepsilon$-caprolactone), F denotes natural hemp fibers and the numbers represent the fibers percentage content. A reference sample, made of the pristine PCL, was also prepared and denoted as C. During extrusion, basic parameters that include the following were recorded: (i) extruder motor torque (M), (ii) energy consumption (E) by the extruder drive system, (iii) temperature $(\mathrm{T})$ of the material being processed that is measured in the extruder die-head and (iv) pressure (P) of the material being processed that is measured in the extruder die-head.

The dumbbell-shaped and bar-shaped specimens were prepared according to a relevant standard (PN-EN ISO 527-2:2012) using a screw injection molding machine (Battenfeld Plus 35/75). The temperatures of the plasticising zones I and II of the barrel were $130{ }^{\circ} \mathrm{C}$ and $140{ }^{\circ} \mathrm{C}$, respectively, and the temperature of the injection molding die head was $140{ }^{\circ} \mathrm{C}$. The temperature of the injection mold was $23^{\circ} \mathrm{C}$ and the injection pressure was $157-163 \mathrm{MPa}$ dependent on the kind of composite. The screw rotational speed was constant at $150 \mathrm{~min}^{-1}$.

Sample irradiation was carried out with a linear accelerator type Elektronika 10/10 producing scanned beam of electrons with energy of $10 \mathrm{MeV}$ and of $10 \mathrm{~kW}$ power with the possibility of changing the dose rate by controlling the speed of the conveyer. The accelerator is located at the Institute of Nuclear Chemistry and Technology in Warsaw, Poland. The samples (granulated samples and injection-moulded pieces) were irradiated with doses of 10, 20, 40, 60 or $90 \mathrm{kGy}$. Maximum single doses were $20 \mathrm{kGy}$. This limitation was caused by an increase in temperature of the irradiated material that was equal to ca. $4-7^{\circ} \mathrm{C}$ for single doses of $10 \mathrm{kGy}$. Large single doses cause intensive heating of the material, therefore some additional structural changes may occur. Thus, samples were irradiated with lower doses multiple times. During the irradiation procedure, all the granulated samples and moulded pieces were placed in aluminium containers in single layers of the thickness of up to $2 \mathrm{~cm}$. The containers were put on the conveyor belt moving at the speed of $0.3-1.2 \mathrm{~m} / \mathrm{min}$ under the accelerator scanner. The actual speed was related to the radiation dose absorbed by the polymer material being modified.

The HF structure in the obtained composites was determined by SEM analysis after dissolving the composites in methylene chloride for $24 \mathrm{~h}$ at room temperature and then filtering the fibers fraction and finally drying them at $50{ }^{\circ} \mathrm{C}$ for $24 \mathrm{~h}$.

The HF structure (before and after extrusion) as well as the surface geometrical structure of the sample fractures, including distribution of the dispersed HF phase, were evaluated by SEM using the secondary electron (SE) detector and accelerating voltage of $10 \mathrm{kV}$. The fractures were made in liquid nitrogen. A 5-nm thick gold layer was sputtered on all of the samples to be analysed by SEM. For that purpose, a cathode sputtering apparatus was used, which was equipped with a coating thickness gauge based on a quartz crystal of varying conductivity.

Tensile strength $\left(\sigma_{M}\right)$ and elongation at break $\left(\varepsilon_{B}\right)$ were evaluated according to the PN-EN ISO 527-1:2012 standard by using the extension rate of $10.0 \mathrm{~mm} / \mathrm{min}$. 
Flexural modulus $\left(\mathrm{M}_{\mathrm{f}}\right)$ was measured by the three-point bend test at a bending deflection rate of $5.0 \mathrm{~mm} / \mathrm{min}$. The measurements were carried out in accordance to the PN-EN ISO 178:2011 standard.

Impact strength $\left(\mathrm{a}_{\mathrm{CN}}\right)$ was evaluated according to the PN-EN ISO 179-1:2010 standard.

\section{Results and Discussion}

\subsection{HF Structure in Obtained Composites}

The structure of the HF taken from obtained composites (Figure 2) is significantly different compared to that shown in Figure 1. First of all, the fibers in the obtained composites possess a significantly reduced length and diameter (even 10 times their length). This is due to two reasons. Firstly, the lengths of the fibers were shortened by the use of a plasticising system containing elements that induced intense mixing and shearing, as well as retracting elements. These elements divided the fibers into smaller particles, including single macrofibrils and, as a result, a fine fraction with high dispersion in the polymer matrix was obtained. Secondly, some of the fibers were additionally shortened in the granulation process.
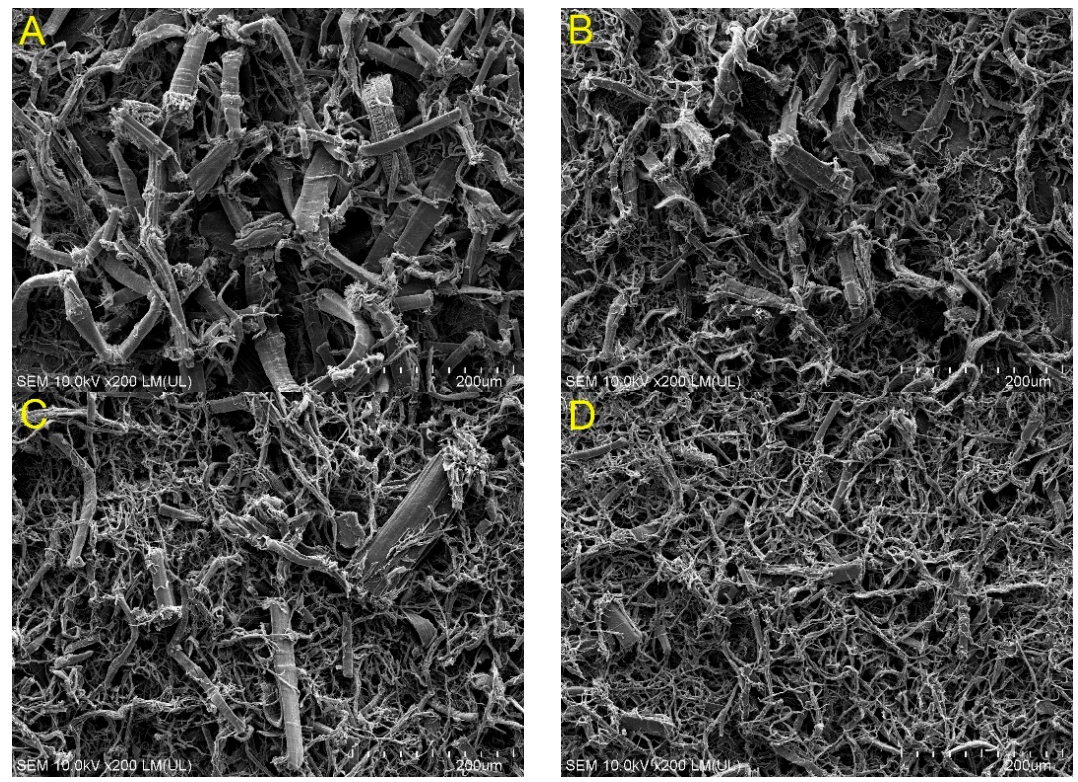

Figure 2. HF structure after extraction from PCL/HF composites ((A) CF2.5; (B) CF5; (C) CF10; (D) CF20).

The fibers in the CF2.5 composite (Figure 2A) have a larger diameter and a more uniform structure compared to the fibers in the other composites. Here and there, a single fiber bundle can be seen. As the composite fiber content increases, their structure changes. At the highest percentage filling, there are a few coarse fibers with intact structure and the dominant fraction is composed of single fiber bundles or individual macrofibrils (Figure 2D).

The change in the fiber structure in individual composites is related to the changing processing parameters, which in turn are a derivative of the increasing fiber content in the plasticised polymer mass. As the content of HF in the composite increases, all the measured parameters of the extrusion process, i.e., $\mathrm{M}, \mathrm{E}, \mathrm{T}$ and $\mathrm{P}$ also increase (Table 1). The increase in these parameters, which are indirectly related to the increase in shear forces, result in changes in the structure of the fibers as shown in Figure 2. Thus, the structure of the obtained fibers may have a significant impact on the mechanical properties of the irradiated PCL/HF composites, which are discussed in Section 3.3. 
Table 1. The extrusion process parameters for PCL and its composites with HF.

\begin{tabular}{ccccc}
\hline Sample & $\mathbf{M} \mathbf{( N m )}$ & $\mathbf{E}(\mathbf{k W})$ & $\mathbf{T}\left({ }^{\circ} \mathbf{C}\right)$ & $\mathbf{P}(\mathbf{M P a})$ \\
\hline C & $16-17$ & $0.95-0.97$ & 165 & $10-11$ \\
CF2.5 & $18-20$ & $0.98-1.02$ & 166 & $12-14$ \\
CF5 & $20-21$ & $1.01-1.05$ & 168 & $14-17$ \\
CF10 & $21-22$ & $1.04-1.08$ & 170 & $16-19$ \\
CF20 & $22-23$ & $1.06-1.11$ & 171 & $20-24$ \\
\hline
\end{tabular}

\subsection{Composites Structure}

The structural analysis results of two selected composites (CF2.5 and CF20) by scanning electron microscopy (SEM) are shown in Figure 3.
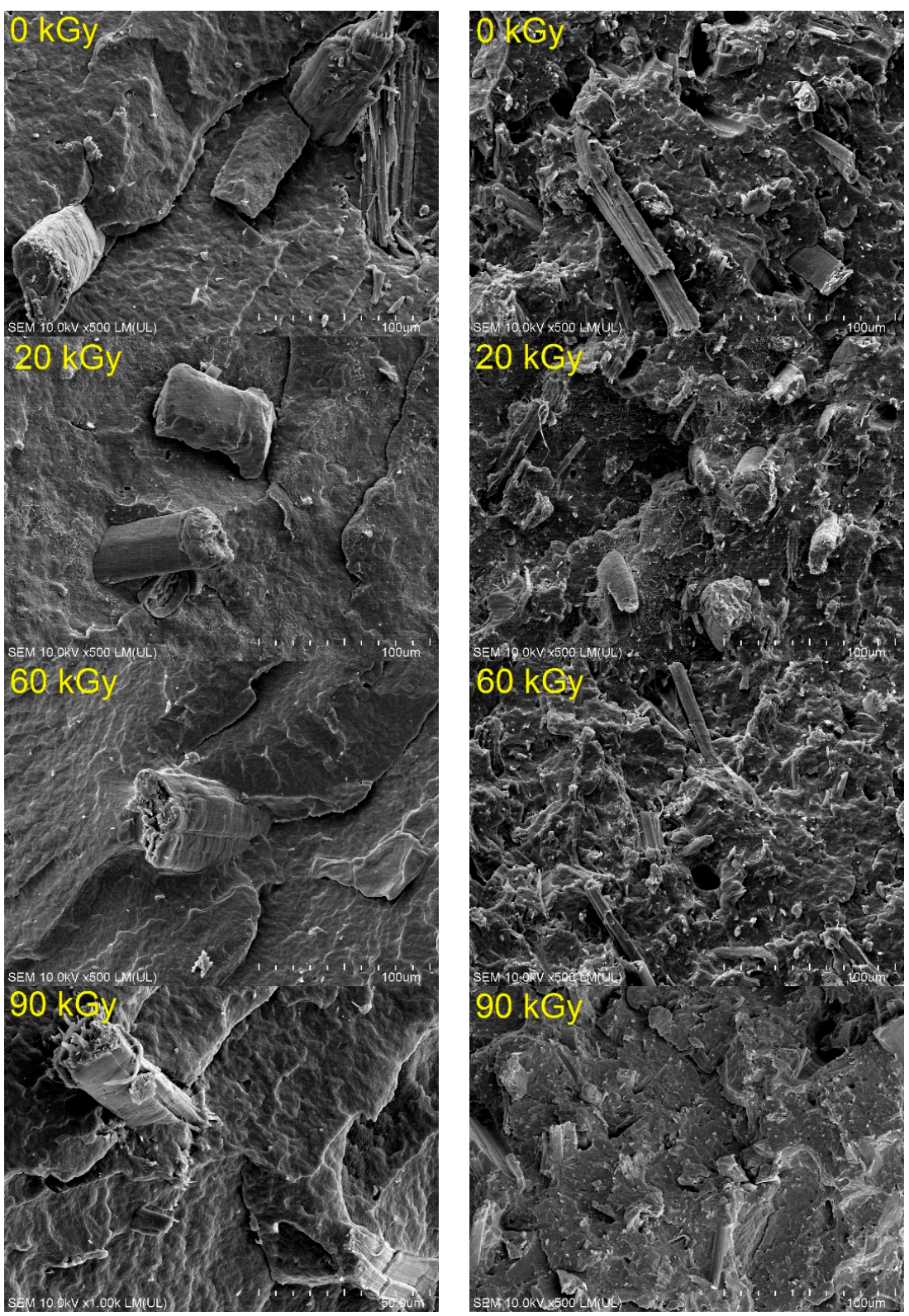

Figure 3. Structure of selected fracture surfaces of bar-shaped specimens obtained from nonirradiated and irradiated CF2.5 (left) and CF20 (right) composites.

Based on the images of the structures shown in Figure 3, it can be concluded that all fractures are brittle fractures. Moreover, the nature of these breakthroughs does not change 
with an increasing radiation dose. In general, all images obtained for composites with the same degree of fiber filling, i.e., $2.5 \%$ or $20 \%$, have comparable structures. This proves that an increase in the radiation dose does not cause significant changes in the fracture structure of composites with a specific HF content. Subtle changes can only be found when assessing the adhesion at the polymer-fiber interface. With an increasing radiation dose, the distance between the phases slightly decreases, which is especially visible in the case of sample CF2.5. On one hand, it may be caused by an increase in thermal expansion of the irradiated material, mainly of the polymer phase, as a result of the temperature increase. On the other hand, it may be related to lower secondary shrinkage due to the changes in the structure of macromolecules after irradiation. Figure 3 also shows that the fibers in composites with a higher percentage filling are finer, which is consistent with the data shown in Figure 2. The craters seen in some photos may come from the extraction of the fibers from the matrix during the fractures. These craters do not disadvantage the material, but are merely a replica of the other half of the sample. The surface structures of the other composites (CF5 and CF10) are very similar and therefore they are not shown here.

\subsection{Mechanical Properties}

The mechanical properties test results of non-modified PCL and PCL/HF composites, as well as irradiated PCL and irradiated PCL/HF composites are illustrated in 3D threedimensional graphs (Figures 4-7) and summarized in Table 2. The three-dimensional graphs (3D) were made using STATISTICA version 10.0 software (StatSoft).

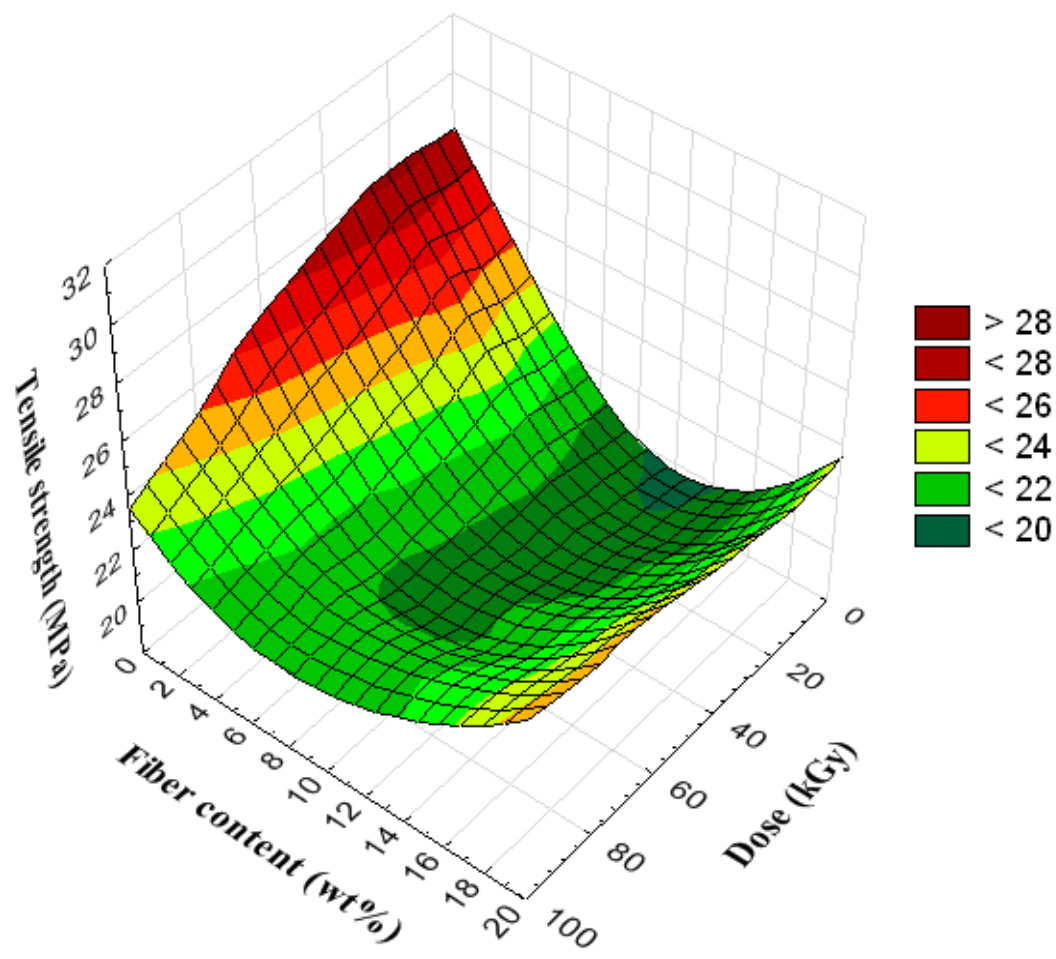

Figure 4. Tensile strength results. 


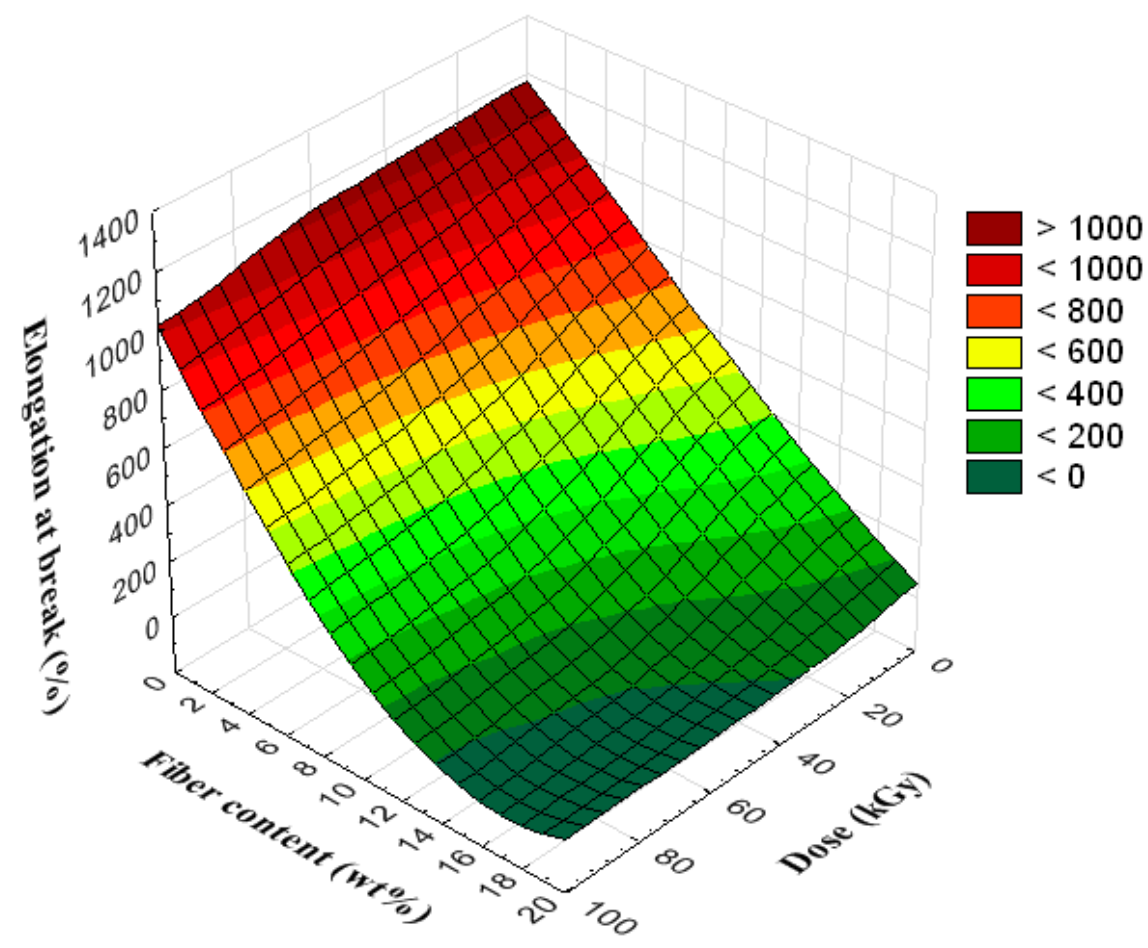

Figure 5. Elongation at break results.

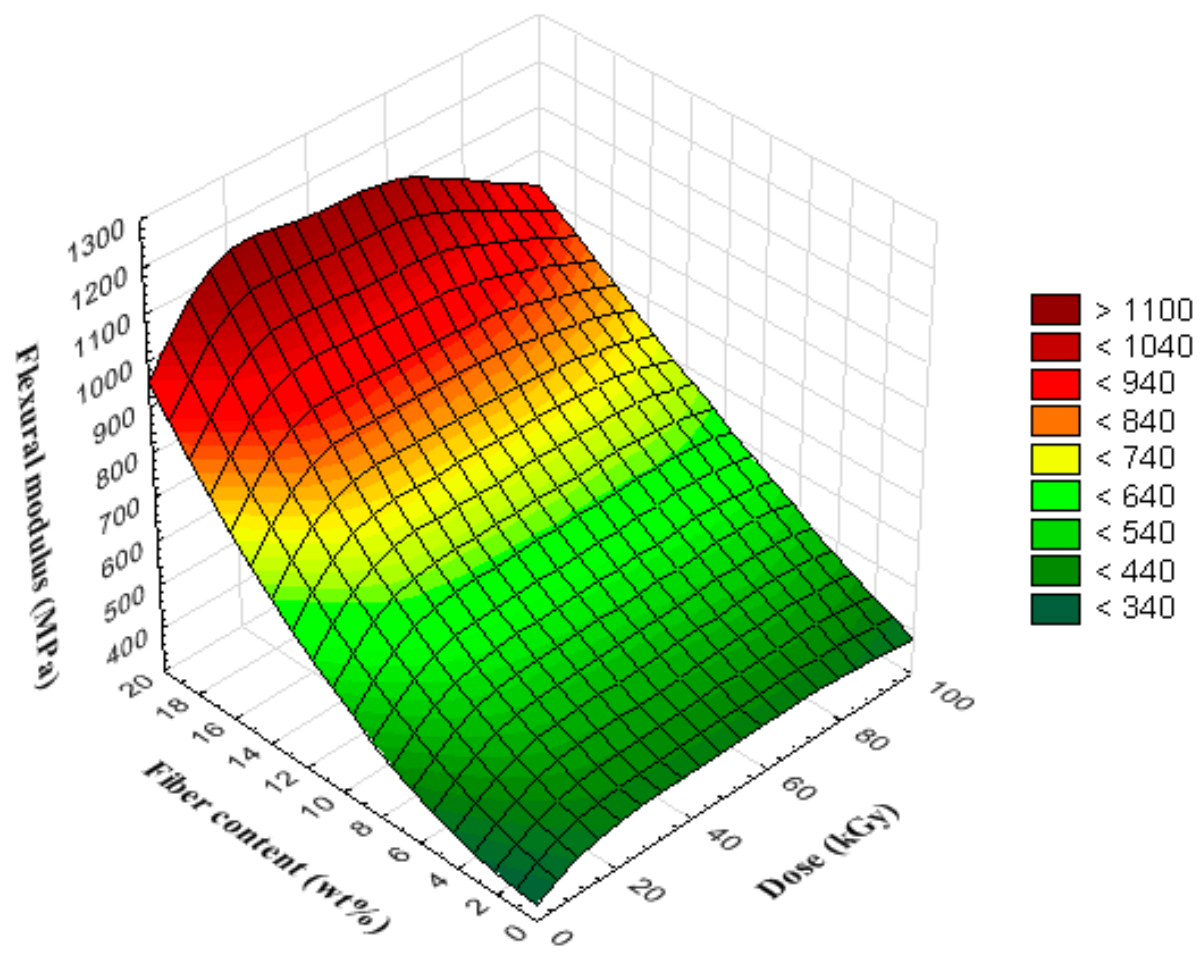

Figure 6. Flexural modulus results. 


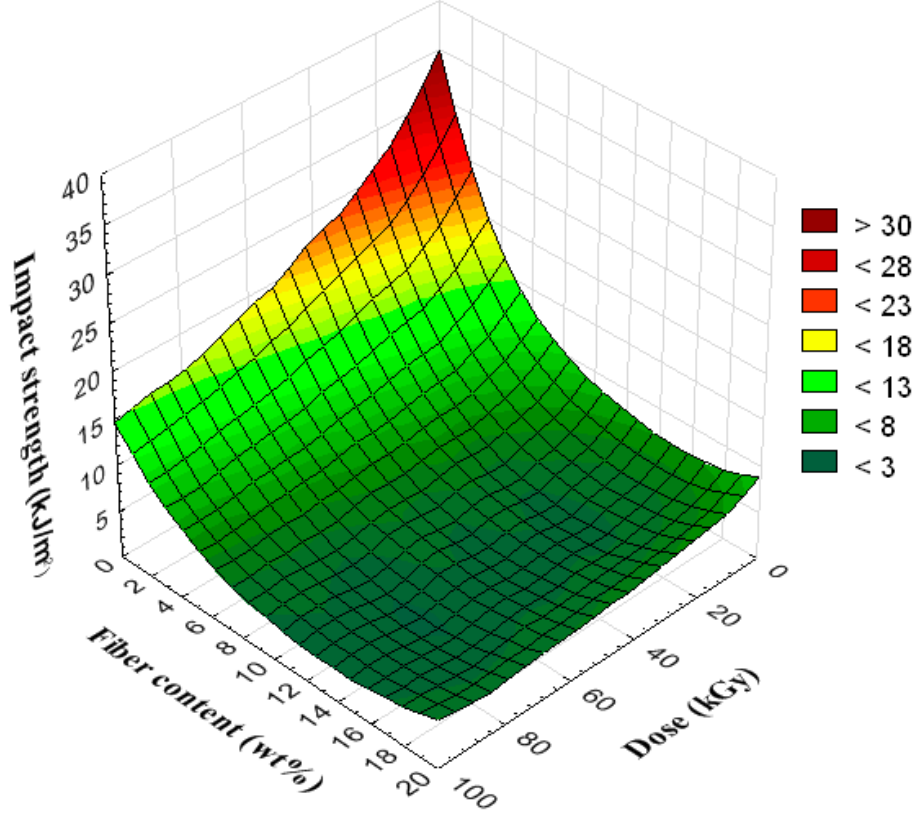

Figure 7. Impact strength results.

Table 2. Mechanical properties of pristine PCL, PCL/HF composites, irradiated PCL and irradiated PCL/HF composites.

\begin{tabular}{cccccc}
\hline Sample & Dose $\mathbf{( k G y )}$ & $\boldsymbol{\sigma}_{\mathbf{M}} \mathbf{( M P a )}$ & $\boldsymbol{\varepsilon}_{\mathbf{B}} \mathbf{( \% )}$ & $\mathbf{M}_{\mathbf{f}} \mathbf{( M P a )}$ & $\mathbf{a}_{\mathbf{c N}} \mathbf{( k J / \mathbf { m } ^ { 2 } )}$ \\
\hline C & 0 & $27.0 \pm 0.9$ & $1091 \pm 24$ & $351 \pm 26$ & $39.4 \pm 0.2$ \\
CF2.5 & 0 & $27.6 \pm 0.5$ & $1105 \pm 52$ & $362 \pm 35$ & $15.7 \pm 0.1$ \\
CF5 & 0 & $23.4 \pm 0.8$ & $910 \pm 9$ & $395 \pm 69$ & $12.9 \pm 0.3$ \\
CF10 & 0 & $19.7 \pm 0.4$ & $518 \pm 71$ & $635 \pm 68$ & $11.4 \pm 0.1$ \\
CF20 & 0 & $23.6 \pm 0.3$ & $48 \pm 8$ & $880 \pm 64$ & $8.8 \pm 0.1$ \\
C & 10 & $27.7 \pm 0.8$ & $1128 \pm 24$ & $381 \pm 21$ & $33.8 \pm 0.2$ \\
CF2.5 & 10 & $26.2 \pm 0.4$ & $1077 \pm 43$ & $396 \pm 42$ & $12.0 \pm 0.2$ \\
CF5 & 10 & $23.6 \pm 0.3$ & $836 \pm 25$ & $487 \pm 38$ & $10.7 \pm 0.2$ \\
CF10 & 10 & $20.0 \pm 0.1$ & $527 \pm 45$ & $635 \pm 68$ & $8.7 \pm 0.1$ \\
CF20 & 10 & $23.4 \pm 0.9$ & $28 \pm 1$ & $1158 \pm 68$ & $7.1 \pm 0.3$ \\
C & 20 & $27.3 \pm 0.9$ & $1096 \pm 26$ & $392 \pm 21$ & $29.5 \pm 0.1$ \\
CF2.5 & 20 & $28.1 \pm 0.4$ & $1064 \pm 70$ & $435 \pm 32$ & $10.4 \pm 0.1$ \\
CF5 & 20 & $24.2 \pm 0.7$ & $820 \pm 21$ & $499 \pm 41$ & $9.5 \pm 0.2$ \\
CF10 & 20 & $20.0 \pm 1.1$ & $364 \pm 41$ & $639 \pm 78$ & $7.8 \pm 0.1$ \\
CF20 & 20 & $23.3 \pm 0.8$ & $26 \pm 2$ & $1220 \pm 22$ & $6.5 \pm 0.3$ \\
C & 40 & $27.7 \pm 1.1$ & $1076 \pm 43$ & $399 \pm 31$ & $25.2 \pm 0.1$ \\
CF2.5 & 40 & $24.8 \pm 1.2$ & $966 \pm 76$ & $433 \pm 12$ & $9.0 \pm 0.1$ \\
CF5 & 40 & $23.1 \pm 0.6$ & $811 \pm 7$ & $502 \pm 29$ & $8.3 \pm 0.2$ \\
CF10 & 40 & $20.6 \pm 0.5$ & $194 \pm 70$ & $640 \pm 73$ & $6.8 \pm 0.2$ \\
CF20 & 40 & $23.8 \pm 1.2$ & $9 \pm 4$ & $1080 \pm 72$ & $5.6 \pm 0.2$ \\
C & 60 & $26.1 \pm 1.1$ & $1073 \pm 74$ & $394 \pm 16$ & $21.0 \pm 0.1$ \\
CF2.5 & 60 & $25.8 \pm 0.7$ & $951 \pm 71$ & $457 \pm 20$ & $7.9 \pm 0.1$ \\
CF5 & 60 & $20.4 \pm 0.3$ & $648 \pm 35$ & $507 \pm 55$ & $7.4 \pm 0.2$ \\
CF10 & 60 & $21.4 \pm 0.7$ & $141 \pm 49$ & $636 \pm 61$ & $6.2 \pm 0.1$ \\
CF20 & 60 & $24.3 \pm 0.4$ & $6 \pm 1$ & $1146 \pm 81$ & $5.0 \pm 0.1$ \\
C & 90 & $23.6 \pm 1.3$ & $903 \pm 65$ & $404 \pm 22$ & $17.3 \pm 0.3$ \\
CF2.5 & 90 & $24.5 \pm 1.9$ & $954 \pm 38$ & $419 \pm 30$ & $6.8 \pm 0.1$ \\
CF5 & 90 & $19.8 \pm 0.1$ & $633 \pm 26$ & $498 \pm 49$ & $6.4 \pm 0.3$ \\
CF10 & 90 & $22.0 \pm 0.3$ & $41 \pm 25$ & $687 \pm 52$ & $5.3 \pm 0.1$ \\
CF20 & 90 & $24.6 \pm 0.4$ & $5 \pm 1$ & $951 \pm 72$ & $4.6 \pm 0.1$ \\
\hline
\end{tabular}


The data from Figure 4 indicates that the tensile strength $\left(\sigma_{M}\right)$ for PCL significantly decreases when the dose of electron radiation is 60 or $90 \mathrm{kGy}$. The decrease is 3\% and 13\%, respectively. Smaller doses of irradiation do not affect the $\sigma_{M}$ of that polymer.

Other dependencies can be observed in the case of non-irradiated composites containing HF. In their case, the $\sigma_{M}$ initially decreases with the rising HF content and then increases. In Figure 4 there is a clear extreme of strength, the lowest value of which can be observed in the $10 \% \mathrm{HF}$ content composite. When compared to pristine PCL, filling composites with $10 \%$ HF causes a decrease in $\sigma_{M}$ by $27 \%$. Larger amounts of HF do not cause a further decrease in $\sigma_{M}$, but they are the reason for its increase of $20 \%$, compared to the CF10 sample. However, the $\sigma_{M}$ value of the non-irradiated CF20 composite is not larger than the $\sigma_{M}$ value of any PCL sample irradiated with doses ranging from 10 to $90 \mathrm{kGy}$ and it is at most equal to the strength of the PCL irradiated with the dose of $90 \mathrm{kGy}$.

Similar observations are seen in the case of irradiated PCL/HF composites, i.e., for a given dose, as the content of $\mathrm{HF}$ in polymer matrix increases, the $\sigma_{\mathrm{M}}$ initially decreases and then increases. However, in this case, the minimum $\sigma_{M}$ value of irradiated composites depends on the irradiation dose. For doses of 10, 20 and $40 \mathrm{kGy}$, the minimum occurs in composites with 10\% HF filling. In the case of doses of 60 and $90 \mathrm{kGy}$, the minimum occurs in composites containing 5\% HF. Moreover, in composites containing 10 or $20 \% \mathrm{HF}$, an increase in $\sigma_{\mathrm{M}}$ with an increasing dose is observed, which is not observed in composites with smaller fiber content.

Elongation at break $\left(\varepsilon_{\mathrm{B}}\right)$ results for the same samples analysed in $\sigma_{\mathrm{M}}$ tests are presented in Figure 5.

Figure 5 shows that both types of modification applied (irradiation and/or addition of $\mathrm{HF}$ ) significantly reduces the $\varepsilon_{\mathrm{B}}$ value. Elongation decreases both as the electron radiation dose increases and when HF content increases and especially when both of these factors occur simultaneously. Elongation is least influenced by electron radiation, which reduces its value by a maximum of $17 \%$ for samples irradiated with $90 \mathrm{kGy}$. The decrease in elongation at break following electron radiation may result from elongation of the macromolecules due to mutual linking at chain ends or the formation of branched structures in notable amounts [50]. HF induces a significantly higher effect on the $\varepsilon_{B}$ value, where a maximum decrease of $95 \%$ is noted. The highest influence on the $\varepsilon_{\mathrm{B}}$ value of the studied polymer is the combined action of electron radiation and HF, which reduces $\varepsilon_{B}$ by as much as $99 \%$. There is, at least, a 100 times decrease in the $\varepsilon_{B}$ value in comparison to non-modified PCL and this occurs in composites with $20 \%$ HF content and that were irradiated with doses of 40,60 or $90 \mathrm{kGy}$.

The data in Figure 6 indicates that electron radiation in a dose of $90 \mathrm{kGy}$ causes a growth in PCL's flexural modulus $\left(\mathrm{M}_{\mathrm{f}}\right)$ value by up to $13 \%$. Smaller doses cause similar increases where the growth is ca. 11-12\%. The flexural modulus of PCL/HF composites increases as the HF content increases. This rate of growth can be considered an exponential function, i.e., at low HF concentration ( 2.5 or $5 \%$ ) the modulus increases slightly. However, in the case of a filling with more than $10 \%$, a significant growth in its value is observed. The $\mathrm{M}_{\mathrm{f}}$ value of the composite containing 20\% HF is over two times greater than the modulus of pristine PCL. This knowledge has significant importance on the eventual suitable range of application for these types of composites.

Irradiation of PCL/HF composites affects their $\mathrm{M}_{\mathrm{f}}$ values. When the radiation dose is $10 \mathrm{kGy}$, a significant increase in the $\mathrm{M}_{\mathrm{f}}$ value is observed. Higher doses do not have a considerable influence on the further growth of modulus values. Differences in $\mathrm{M}_{\mathrm{f}}$ values of composites irradiated with doses of 20,40 or $60 \mathrm{kGy}$ do not differ notably from each other (Table 2). An exception to this is the case of when the CF20 composite is irradiated with $90 \mathrm{kGy}$ and its $\mathrm{M}_{\mathrm{f}}$ value decreases slightly. This may be due to degradation of both composite phases and, in particular, the HF phase. We can assume this because no decrease in the $\mathrm{M}_{\mathrm{f}}$ value was observed for lower fiber contents.

The impact strength $\left(\mathrm{a}_{\mathrm{cN}}\right)$ of PCL shown in Figure 7 decreases significantly as the radiation dose increases. The maximum decrease in the PCL's impact strength, 56\%, occurs upon 
irradiation of the polymer with $90 \mathrm{kGy}$. This may result from the formation of a branched or partially crosslinked structure of PCL macromolecules that hinders their conformational changes. This, in turn, limits the amount of energy absorbed by the irradiated PCL. Possible limitations for the rotation of macromolecular fragments can also affect other mechanical properties, including $\mathrm{M}_{\mathrm{f}}$ or $\varepsilon_{\mathrm{B}}$, which were presented earlier.

The PCL/HF composites are also characterised by significantly reduced impact strength. It is also worth noting that the highest impact strength of non-irradiated composite (sample CF2.5) is considerably lower than the lowest impact strength value of irradiated PCL. By introducing the amount of just $2.5 \%$ of fibers (sample CF2.5) into the polymer matrix causes a reduction in impact strength by $60 \%$ and the addition of $20 \%$ fibers (sample CF20) reduces its value by $78 \%$. Therefore, it can be concluded that the impact strength of PCL is more significantly influenced by even a minimal amount $(2.5 \mathrm{wt} \%)$ of fibers introduced into the polymer matrix than by electron radiation with the highest applied dose (90 kGy).

In the case of irradiated PCL/HF composites, further decreases in impact strength are observed. However, while present, the changes in impact strength of the composite after irradiation are less significant. For example, the impact strength of the CF2.5 composite after irradiation with the maximum dose ( $90 \mathrm{kGy}$ ) decreases by a maximum of $83 \%$ compared to the impact strength of pristine PCL. Thus, irradiation decreases the impact strength of PCL by an additional 23\% compared to the non-irradiated CF2.5 composite. In turn, the impact strength of the composite containing the maximum amount of fibers (sample CF20) and irradiated with the maximum dose (90 kGy) decreases by a maximum of $88 \%$ compared to the impact strength of pristine PCL. For this composite (CF20), irradiation decreases the impact strength of PCL by an additional 10\% compared to the non-irradiated CF20 composite.

The data in Table 2 indicates that large relative changes occur in the impact strength values for individual composites after irradiation. For example, doses of 10 and $90 \mathrm{kGy}$ led to a decrease in the impact strength of the CF2.5 composite by $24 \%$ and $57 \%$, respectively. Moreover, an increase in the HF weight fraction in the PCL matrix causes a decrease in the relative differences in impact strength for composites after irradiation. For example, the doses of 10 and $90 \mathrm{kGy}$ decreases the impact strength of CF20 composite by $19 \%$ and $48 \%$, respectively. The significant reduction in the impact strength of non-irradiated and irradiated PCL/HF composites results mainly from the stiffening of the material and the perpendicular orientation of the natural fibers (Figure 3) in relation to the impact force applied by the hammer during strength testing.

\section{Conclusions}

The structure and mechanical properties of the investigated materials depended on three main factors: (i) processing conditions, (ii) qualitative and quantitative contribution of dispersed phase and (iii) the magnitude of the electron radiation dose. The final fibers' structures in the obtained composites were closely linked to processing conditions, which also depended on the percentage filling of these fibers in the polymer matrix. Electron radiation did not significantly change the structure of the prepared composites. Only small changes could be observed in the case of adhesion between the dispersed phase and the polymer matrix. The structure of the composites, however, depended significantly on the HF content. Mechanical properties of the study's composites were greatly influenced by electron radiation. Furthermore, as the radiation dose increased, the values of impact strength, elongation at break and in part tensile strength decreased while the flexural modulus increased. An especially interesting synergistic effect on PCL properties was observed and was related to the combined action of electron radiation and natural fibers addition. For example, depending on the used dose and fibers amount, elongation at break can be reduced from $1 \%$ to $99 \%$, while the flexural modulus can increase from $1 \%$ to $248 \%$.

Hemp fibers may be used as an additive in the PCL matrix to manufacture biodegradable materials. Ecological advantages and the low price of these fibers compared to the 
price of PCL highlight a direction for further research in this field. Moreover, the applied fibers should additionally accelerate the biodegradation process of such materials. This statement refers, specifically, to radiation-modified biodegradable polymers that can be partially crosslinked and, as consequence of this, the biodegradation process may be slowed down. Thus, hemp fibers should lessen the adverse effect that crosslinking has on biodegradability. In this case, further studies determining the combined action of electron radiation and natural fibers on the biodegradation of these materials may be interesting. Furthermore, the post-radiation oxidation processes of both the matrix and HF as well as the protective effect of lignin in the obtained materials may also be the subject of further research. The radiation-modified composites presented in this article can be applied primarily for the production of biodegradable packaging, including rigid and flexible ones, depending on the applied radiation dose and the fibers content.

Author Contributions: Conceptualization, R.M. and V.K.; methodology, R.M., K.M. and W.G.; sample preparation, R.M. and W.G.; formal analysis, A.R.-K. and V.K.; investigation, R.M., A.R.-K. and K.M.; data curation, R.M.; writing-original draft preparation, R.M. and A.R.-K.; writing-review and editing, R.M. and L.W. All authors have read and agreed to the published version of the manuscript.

Funding: The project has been financed by statutory funds (project no. 110034).

Institutional Review Board Statement: Not applicable.

Informed Consent Statement: Not applicable.

Data Availability Statement: All experimental data to support the findings of this study are available upon request by contacting the corresponding author.

Acknowledgments: The authors of this work would like to express their special thanks to the Institute of Natural Fibers and Medicinal Plants in Poznan (Poland) for the preparation of hemp fibers.

Conflicts of Interest: The authors declare no conflict of interest.

\section{References}

1. Mohamed, R.M.; Yusoh, K. A review on the recent research of polycaprolactone (PCL). Adv. Mater. Res. 2016, 1134, 249-255. [CrossRef]

2. Woodruff, M.A.; Hutmacher, D.W. The return of a forgotten polymer-Polycaprolactone in the 21st century. Prog. Polym. Sci. 2010, 35, 1217-1256. [CrossRef]

3. Labet, M.; Thielemans, W. Synthesis of polycaprolactone: A review. Chem. Soc. Rev. 2009, 38, 3484-3504. [CrossRef]

4. Bastioli, C.; Cerruti, A.; Guanella, I.; Romano, G.C.; Tosin, M.J. Physical state and biodegradation behavior of starchpolycaprolactone systems. Environ. Polym. Degrad. 1995, 3, 81-95. [CrossRef]

5. Amass, W.; Amass, A.; Tighe, B. A Review of Biodegradable Polymers: Uses, Current Developments in the Synthesis and Characterization of Biodegradable Polyesters, Blends of Biodegradable Polymers and Recent Advances in Biodegradation Studies. Polym. Int. 1998, 47, 89-144. [CrossRef]

6. Van de Velde, K.; Kiekens, P. Biopolymers: Overview of several properties and consequences on their applications. Polym. Test. 2002, 21, 433-442. [CrossRef]

7. Follaina, N.; Belbekhouchea, S.; Brasb, J.; Siqueirab, G.; Chappeya, C.; Maraisa, S.; Dufresne, A. Tunable gas barrier properties of filled-PCL film by forming percolating cellulose network. Colloids Surf. A 2018, 545, 26-30. [CrossRef]

8. Mellinas, C.; Ramos, M.; Grau-Atienza, A.; Jordà, A.; Burgos, N.; Jiménez, A.; Serrano, E.; Garrigós, M.C. Biodegradable Poly(ECaprolactone) Active Films Loaded with MSU-X Mesoporous Silica for the Release of $\alpha$-Tocopherol. Polymers 2020, $12,137$. [CrossRef] [PubMed]

9. Zaaba, N.F.; Jaafar, M. A review on degradation mechanisms of polylactic acid: Hydrolytic, photodegradative, microbial, and enzymatic degradation. Polym. Eng. Sci. 2020, 60, 2061-2075. [CrossRef]

10. Sonchaeng, U.; Iniguez-Franco, F.; Auras, R.; Selke, S.; Rubino, M.; Lim, L.T. Poly(lactic acid) mass transfer properties. Prog. Polym. Sci. 2018, 86, 85-121. [CrossRef]

11. Castro-Aguirre, E.; Iniguez-Franco, F.; Samsudin, H.; Fang, X.; Auras, R. Poly(lactic acid)—Mass production, processing, industrial applications, and end of life. Adv. Drug Deliver. Rev. 2016, 107, 333-366. [CrossRef]

12. Ahmed, J.; Varshney, S.K. Polylactides-Chemistry, Properties and Green Packaging Technology: A Review. Int. J. Food Prop. 2011, 14, 37-58. [CrossRef]

13. Lim, L.T.; Auras, R.; Rubino, M. Processing technologies for poly(lactic acid). Prog. Polym. Sci. 2008, 33, 820-852. [CrossRef]

14. Ge, C.; Lansing, B.; Lewis, C.L. Thermoplastic starch and poly(vinyl alcohol) blends centered barrier film for food packaging applications. Food Packag. Shelf Life 2021, 27, 100610. [CrossRef] 
15. Cuevas-Carballo, Z.B.; Duarte-Aranda, S.; Canché-Escamilla, G. Properties and Biodegradability of Thermoplastic Starch Obtained from Granular Starches Grafted with Polycaprolactone. Int. J. Polym. Sci. 2017, 2017. [CrossRef]

16. Zhang, Y.; Rempel, C.; Liu, Q. Thermoplastic starch processing and characteristics-A review. Crit. Rev. Food Sci. Nutr. 2014, 54, 1353-1370. [CrossRef]

17. Bajer, K.; Stasiek, A.; Raszkowska-Kaczor, A.; Bajer, D. Extrusion of thermoplastics starch with twin-screw extruders. Przem. Chem. 2014, 93, 192-195.

18. Averous, L.; Moro, L.; Dole, P.; Fringant, C. Properties of thermoplastic blends: Starch-polycaprolactone. Polymer 2000, 41, 4157-4167. [CrossRef]

19. Avella, M.; Errico, M.E.; Laurienzo, P.; Martuscelli, E.; Raimo, M.; Rimedio, R. Preparation and characterisation of compatibilised polycaprolactone/starch composites. Polymer 2000, 41, 3875-3881. [CrossRef]

20. Wu, C.S. Physical properties and biodegradability of maleated-polycaprolactone/starch composite. Polym. Degrad. Stab. 2003, 80, 127-134. [CrossRef]

21. Chavalitpanya, K.; Phattanarudee, S. Poly(Lactic Acid)/Polycaprolactone Blends Compatibilized with Block Copolymer. Energy Procedia 2013, 34, 542-548. [CrossRef]

22. Ostafinska, A.; Fortelny, I.; Nevoralova, M.; Hodan, J.; Kredatusova, J.; Slouf, M. Synergistic effects in mechanical properties of PLA/PCL blends with optimized composition, processing, and morphology. RSC Adv. 2015, 5, 98971-98982. [CrossRef]

23. Dell'Erba, R.; Groeninckx, G.; Maglio, G.; Malinconico, M.; Milgliozzi, A. Immiscible polymer blends of semicrystalline biocompatible components: Thermal properties and phase morphology analysis of PLLA/PCL blends. Polymer 2001, 42, 7831-7840. [CrossRef]

24. Patrício, T.; Domingos, M.; Gloria, A.; Bártolo, P. Characterisation of PCL and PCL/PLA scaffolds for tissue engineering. Procedia CIRP 2013, 5, 110-114. [CrossRef]

25. Sousa, F.M.; Costa, A.R.M.; Reul, L.T.; Cavalcanti, F.B.; Carvalho, L.H.; Almeida, T.G.; Canedo, E.L. Rheological and thermal characterisation of PCL/PBAT blends. Polym. Bull. 2018, 76, 1573-1593. [CrossRef]

26. Daenin, R.D.; Zhang, Z.-B. Polycaprolactone as permanent plasticizer for poly(vinyl chloride). J. Vinyl Technol. 1984, 6, 18-21. [CrossRef]

27. Saeed, K.; Park, S.Y. Preparation and Properties of Polycaprolactone/Poly(Butylene Terephthalate) Blend. Iran. J. Chem. Chem. Eng. 2010, 29, 77-81.

28. Liang, J.Z.; Duan, D.R.; Tang, C.Y.; Tsui, C.P.; Chen, D.Z. Flexural Properties of Poly-L-Lactide and Polycaprolactone Shape Memory Composites Filled with Nanometer Calcium Carbonate. J. Macromol. Sci. B 2013, 52, 964-972. [CrossRef]

29. Wu, T.; Xie, T.; Yang, G. Preparation and characterization of poly( $\varepsilon$-caprolactone)/ $\mathrm{Na}^{+}-\mathrm{MMT}$ nanocomposites. Appl. Clay Sci. 2009, 45, 105-110. [CrossRef]

30. Van der Schueren, L.; De Meyer, T.; Steyaert, I.; Ceylan, O.; Hemelsoet, K.; Van Speybroeck, V.; De Clerck, K. Polycaprolactone and polycaprolactone/chitosan nanofibres functionalised with the $\mathrm{pH}$-sensitive dye Nitrazine Yellow. Carbohydr. Polym. 2013, 91, 284-293. [CrossRef] [PubMed]

31. Arbelaiz, A.; Fernández, B.; Valea, A.; Mondragon, I. Mechanical properties of short flax fibre bundle/poly( $(\varepsilon$-caprolactone) composites: Influence of matrix modification and fibre content. Carbohydr. Polym. 2006, 64, 224-232. [CrossRef]

32. Shibata, M.; Yosomiya, R.; Ohta, N.; Sakamoto, A.; Takeishi, H. Poly(E-caprolactone) composites reinforced with short abaca fibres. Polym. Compos. 2003, 11, 359-367. [CrossRef]

33. Pan, P.; Zhu, B.; Dong, T.; Serizawa, S.; Iji, M.; Inoue, Y. Kenaf fiber/poly( $\varepsilon$-caprolactone) biocomposite with enhanced crystallization rate and mechanicalproperties. J. Appl. Polym. Sci. 2008, 107, 3512-3519. [CrossRef]

34. Rytlewski, P.; Stepczyńska, M.; Moraczewski, K.; Malinowski, R.; Jagodziński, B.; Żenkiewicz, M. Mechanical properties and biodegradability of flax fiber-reinforced composite of polylactide and polycaprolactone. Polimery 2018, 63, 603-610. [CrossRef]

35. Berzin, F.; Vergnes, B.; Beaugrand, J. Evolution of lignocellulosic fibre lengths along the screw profile during twin screw compounding with polycaprolactone. Compos. Part A Appl. Sci. Manuf. 2014, 59, 30-36. [CrossRef]

36. Duan, K.; Chen, H.; Huang, J.; Yu, J.; Liu, S.; Wang, D.; Li, Y. One-step synthesis of amino-reserved chitosan-graft-polycaprolactone as a promising substance of biomaterial. Carbohydr. Polym. 2010, 80, 498-503. [CrossRef]

37. Wang, Z.; Zheng, L.; Li, C.; Zhang, D.; Xiao, Y.; Guan, G.; Zhu, W. A novel and simple procedure to synthesize chitosan-graftpolycaprolactone in an ionic liquid. Carbohydr. Polym. 2013, 94, 505-510. [CrossRef]

38. Li, Z.; Tan, B.H. Towards the development of polycaprolactone based amphiphilic block copolymers: Molecular design, selfassembly and biomedical applications. Mater. Sci. Eng. C Mater. Biol. Appl. 2014, 45, 620-634. [CrossRef] [PubMed]

39. Lipik, V.T.; Widjaja, L.K.; Liow, S.S.; Abadie, M.J.M.; Venkatraman, S.S. Effects of transesterification and degradation on properties and structure of polycaprolactone-polylactide copolymers. Polym. Degrad. Stab. 2010, 95, 2596-2602. [CrossRef]

40. Narkis, M.; Sibony-Chaouat, S.; Siegmann, A.; Shkolnik, S.; Bell, J.P. Irradiation effects on polycaprolactone. Polymer 1985, 26, 50-54. [CrossRef]

41. Malinowski, R. Mechanical properties of PLA/PCL blends crosslinked by electron beam and TAIC additive. Chem. Phys. Lett. 2016, 662, 91-96. [CrossRef]

42. Dhakal, H.N.; Ismail, S.O.; Zhang, Z.; Barber, A.; Welsh, E.; Maigret, J.E.; Beaugrand, J. Development of sustainable biodegradable lignocellulosic hemp fiber/polycaprolactone biocomposites for light weight applications. Compos. Part A Appl. Sci. Manuf. 2018, 113, 350-358. [CrossRef] 
43. Dhakal, H.N.; Ismail, S.O.; Beaugrand, J.; Zhang, Z.; Zekonyte, J. Characterization of Nano-Mechanical, Surface and Thermal Properties of Hemp Fiber-Reinforced Polycaprolactone (HF/PCL) Biocomposites. Appl. Sci. 2020, 10, 2636. [CrossRef]

44. Dhakal, H.N.; Bourmaud, A.; Berzin, F.; Almansour, F.; Zhang, Z.; Shah, D.U.; Beaugrand, J. Mechanical properties of leaf sheath date palm fibre waste biomass reinforced polycaprolactone (PCL) biocomposites. Ind. Crop. Prod. 2018, 126, 394-402. [CrossRef]

45. Beaugrand, J.; Berzin, F. Lignocellulosic Fiber Reinforced Composites: Influence of Compounding Conditions on Defibrization and Mechanical Properties. J. Appl. Polym. Sci. 2013, 128, 1227-1238. [CrossRef]

46. Wahit, M.U.; Akos, N.I.; Laftah, W.A. Influence of natural fibers on the mechanical properties and biodegradation of poly(lactic acid) and poly(E-caprolactone) composites: A review. Polym. Compos. 2013, 34, 763-768. [CrossRef]

47. Cottam, E.; Hukins, D.W.L.; Lee, K.; Hewitt, C.; Jenkins, M.J. Effect of sterilisation by gamma irradiation on the ability of polycaprolactone (PCL) to act as a scaffold material. Med. Eng. Phys. 2009, 31, 221-226. [CrossRef] [PubMed]

48. Abdel-Rehim, H.A.; Yoshii, F.; Kume, T. Modification of polycaprolactone in the presence of polyfunctional monomers by irradiation and its biodegradability. Polym. Degrad. Stab. 2004, 85, 689-695. [CrossRef]

49. Yoshii, F.; Darwis, D.; Mitomo, H.; Makuuchi, K. Crosslinking of poly( $\varepsilon$-caprolactone) by radiation technique and its biodegradability. Radiat. Phys. Chem. 2000, 57, 417-420. [CrossRef]

50. Malinowski, R. Effect of electron radiation and triallyl isocyanurate on the average molecular weight and crosslinking of poly(E-caprolactone). Polym. Adv. Technol. 2016, 27, 125-130. [CrossRef]

51. Malinowski, R.; Rytlewski, P.; Janczak, K.; Raszkowska-Kaczor, A.; Moraczewski, K.; Stepczyńska, M.; Żuk, T. Studies on functional properties of PCL films modified by electron radiation and TAIC additive. Polym. Test. 2015, 48, 169-174. [CrossRef]

52. Rytlewski, P.; Stepczyńska, M.; Ghost, U.; Malinowski, R.; Budner, B.; Żenkiewicz, M. Flax fibres reinforced polylactide modified by ionizing radiation. Ind. Crop. Prod. 2018, 112, 716-723. [CrossRef]

53. Rytlewski, P.; Stepczyńska, M.; Moraczewski, K.; Malinowski, R.; Karasiewicz, T.; Sikorska, W.; Żenkiewicz, M. Flax fibres reinforced polycaprolactone modified by triallyl isocyanurate and electron radiation. Polym. Compos. 2019, 40, 481-488. [CrossRef] 